\title{
AN ATTEMPT TO DESCRIBE THE ULTRASTRUCTURE AND ULTRAHISTOCHEMISTRY OF CILIARY PROCESSES IN MAMMALS
}

\author{
Svatopluk Čech
}

Department of Histology and Embryology, Medical Faculty, Masaryk University, Kamenice 3, 62500 Brno, Czech Republic e-mail: scech@med.muni.cz

Received: September 20, 2004

Key words: Ciliary processes/Comparative micromorphology/Glycogen/Mammals

The aim of the present paper was to reexamine fine structural characteristics and glycogen topochemistry of ciliary processes in small laboratory mammals (hamsters, guinea-pigs and mice). A two-layered epithelium continuously covered all ciliary processes. The epithelium consisted of inner nonpigmented and outer pigmented cells whose apices faced each other. They were linked by desmosomes and tight junctions. Basal cell aspects showed extensively interdigitating processes adjacent to the inner (rarely also outer) basal lamina. The ciliary process core was made up of reticular fibers, few fibrocytes, and capillaries with or without fenestrations. No glycogen particles were found in the ciliary epithelium using the PA-TSC-SP procedure.

\section{INTRODUCTION}

Earlier electron microscopic observations showed that a nonpigmented layer of the ciliary epithelium is directly involved in the production of the aqueous humour that occupies the anterior and posterior chambers of the eye. In connection with a research project on the ciliary body, the author decided to compare the fine structure of the ciliary epithelium and ciliary processes in a number of small laboratory animals and to find a suitable and reliable experimental model for directed histo- or ultrahistochemical examination. The aim of this paper is to provide information on the first micromorphological observations including the results of glycogen visualization in the ciliary processes.

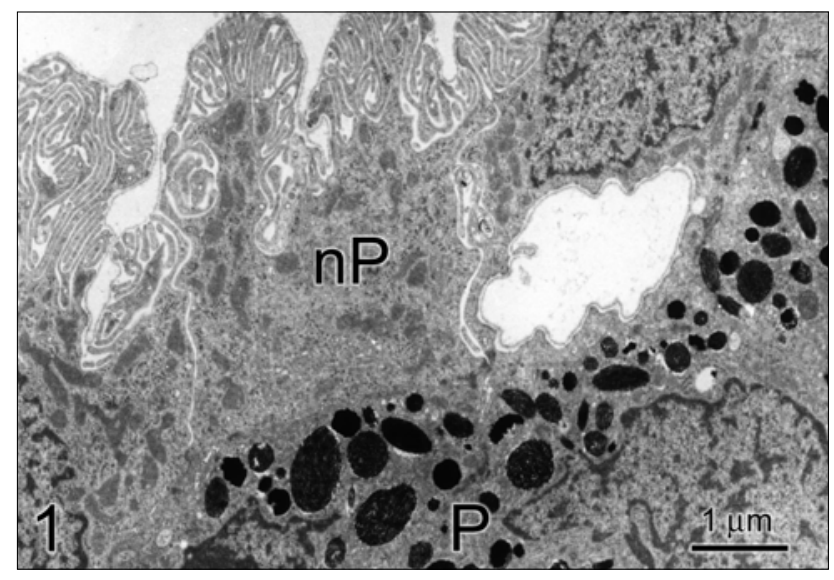

Fig. 1. The hamster: Ciliary epithelium. Note the inner nonpigmented cells (nP) and outer pigmented cells (P) whose apices are faced each other and linked by desmosomes. Bar $=1 \mu \mathrm{m}$.

\section{MATERIAL AND METHODS}

The anterior portions of the ciliary bodies in mice, hamsters and guinea-pigs were dissected, fixed with glutaraldehyde and osmium tetroxide and embedded in Durcupan ACM according to the standard protocol. Thin sections were cut and processed in two ways:

- By the use of conventional staining with uranyl acetate and lead citrate ${ }^{1}$.

- By the periodic acid-thiosemicarbazide-silver proteinate (PA-TSC-SP) procedure for the electron histochemical visualization of glycogen ${ }^{2}$. The PA-TSC-SP specificity was verified by omission of the periodic acid step, diastase digestion and blocking of aldehyde groups with Dimedon (E. Merck/Darmstadt).

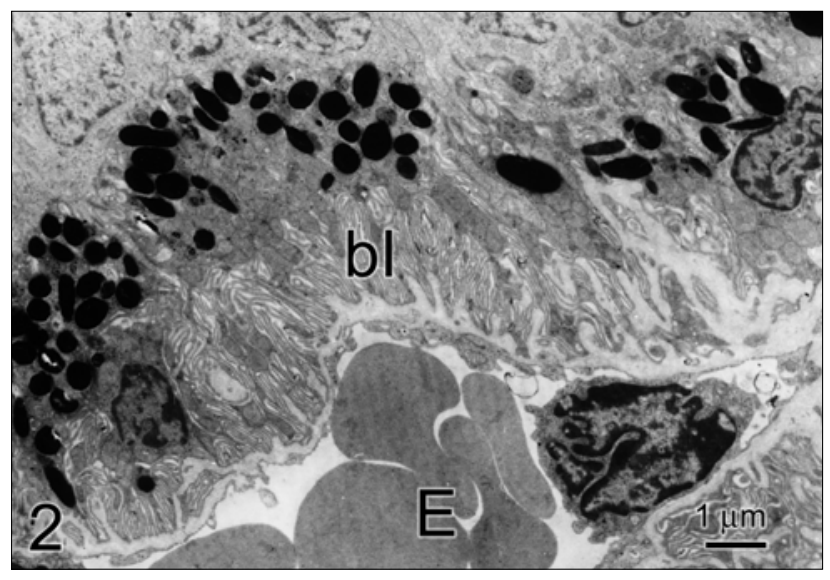

Fig. 2. The mouse: Stroma of a ciliary process. A part of a fenestrated capillary wall surrounded with prominent basal infoldings (bI) of outer pigmented cells. Erythrocyte (E). Bar $=1 \mu \mathrm{m}$. 


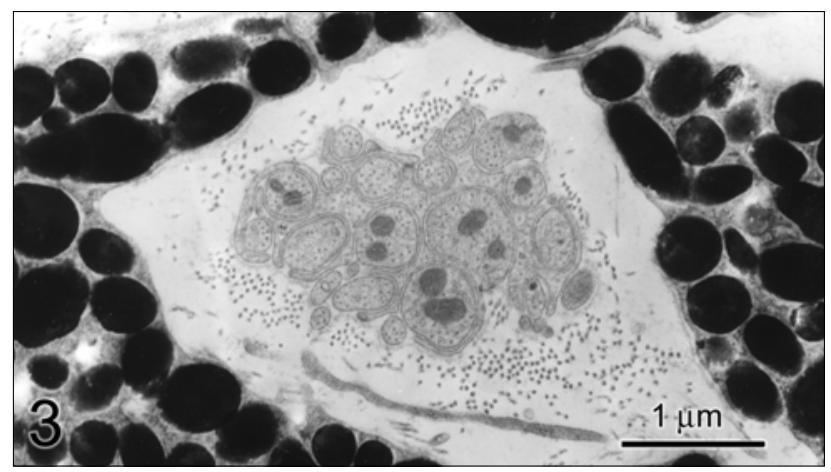

Fig. 3. The mouse: Stroma of a ciliary process containing a Schwann cell with axons. Bar $=1 \mu \mathrm{m}$.

The evaluation and photography of thin sections were carried out on a FEI Morgagni 268D electron microscope at 90 and/or $60 \mathrm{kV}$ (sections for glycogen).

\section{RESULTS AND DISCUSSION}

The ciliary processes were covered by a two-layered ciliary epithelium (Fig. 1). The epithelium consisted of an inner layer of nonpigmented cells facing the posterior chamber and an outer layer of pigmented cells that were in contact with the connective tissue stroma. Both cells were cuboidal or columnar in shape; their apices faced each other and were constantly linked by numerous desmosomes and tight junctions.

Bases of superficial nonpigmented cells were adjacent to the posterior chamber and separated from it by a distinct basal lamina (Fig. 1). Basal infoldings and interdigitations that are continuous with interdigitations of basolateral cell aspects were well developed. Their density showed, as a rule, clear differences in the studied species. Prominent infoldings were especially found in mice and hamsters (Fig. 1). In all examined animals the cytoplasm of nonpigmented cells constantly displayed ribosomes and few spherical mitochondria.

The basal aspect of deep pigmented cells was supported by a basal lamina that appeared to be thinner and poorly developed in comparison with the inner one. In a case of stromal blood capillaries near pigmented cell bases, numerous infoldings and interdigitations of respective basal aspects were usually observed (Fig. 2).

The stroma of ciliary processes was made up of few fibrocytes but numerous reticular fibers and capillaries. In contrast to the guinea-pig in whose ciliary processes capillaries of a continuous type with pericytes had been prevailingly seen, fenestrated capillaries were found in mice and hamsters (Fig. 2). In all species under study were frequently found thin nerve fibers and nerve endings in the stroma of ciliary processes (Fig. 3).

PA-TSC-SP staining for glycogen: No polysaccharide was detected in the ciliary epithelium by the use of the PATSC-SP procedure. On the other hand, solitary glycogen particles, rarely small clusters of them, were constantly found in all stromal fibrocytes.

It is commonly accepted that the ciliary epithelium is engaged in the production of the aqueous humour. The results here confirm that only nonpigmented cells showed a structural basis for water and ion transport in the examined species. On the other hand, prominent infoldings of basal aspects of pigmented cells were restricted to cells localized near blood capillaries in the mouse. For this reason the ciliary processes of this species are recommended as an experimental model.

The absence of glycogen found by the PA-TSC-SP method in the ciliary epithelium is in good accordance with biochemical and light histochemical findings published for the rabbit ciliary body (Asaka et al. ${ }^{3}$ ).

\section{REFERENCES}

1. Reynolds ES. (1963) The use of the lead at high $\mathrm{pH}$ as an electronopaque stain in electron microscopy. J Cell Biol 17, 208-212.

2. Thiéry JP. (1967) Mise en évidence des polysaccharides sur coupes fines en microscopie électronique J Microscopie 6, 987-1018.

3. Asaka Y, Watanabe J, Kanai K, Kanamura S. (1991) High glucose6-phosphatase activity in non-pigmented epithelial cells of rabbit ciliary body. J Histochem Cytochem 39, 1113-1120. 